\title{
PENGARUH LAYANAN ADMINISTRASI TERHADAP KEPUASAN SISWA MTs. UNGGULAN MUKHTAR SYAFA'AT BLOKAGUNG TEGALSARI BANYUWANGI TAHUN PEMBELAJARAN 2019/2020
}

\author{
Moh. Harun Al Rosid ${ }^{1}$, Fila Nurul Arifin ${ }^{2}$ \\ e-mail: harun2939@gmail.com ${ }^{1}$, filaarifin@gmail.com² \\ Prodi Manajemen Pendidikan Islam \\ Institut Agama Islam Darussalam Blokagung Banyuwangi
}

\begin{abstract}
Abstrak
Tujuan dari penelitian ini adalah untuk mengetahui bagaimana kualitas layanan administrasi MTs. Unggulan Mukhtar Syafaat Blokagung Tegalsari Banyuwangi. Kedua, bagaimana tingkat kepuasan siswa MTs. Unggulan Mukhtar Syafaat Blokagung Tegalsari Banyuwangi. Ketiga, adakah pengaruh pelayanan terhadap kepuasan siswa MTs. Unggulan Mukhtar Syafaat Blokagung Tegalsari Banyuwangi. Metode pada penelitian ini menggunakan kuntitatif dengan pengumpulan data yang digunakan dalam penelitian ini ialah angket, observasi, dan dokumentasi. Sedangkan uji validitas data menggunakan rumus Product moment, untuk mencari reliabilitas data menggunakan rumus Cornbach Alpha. Kemudian untuk uji hipotesis menggunakan uji $\mathrm{T}$ dan uji $\mathrm{F}$, sedangkan untuk uji normalitas menggunakan rumus Kolmogorov-Smirnov. Pada analisis data menggunakan analisis Regresi Linier Sederhana. Hasil penelitian ini menunjukkan bahwa: (1) kualitas layanan administrasi MTs. Unggulan Mukhtar Syafaat Blokagung Tegalsari Banyuwangi Tahun Pembelajaran 2019/2020 tergolong cukup baik, karena hasil uji T hitung sebesar 26,038> 1,290 t tabel., yang berarti Ha diterima; (2) tingkat kepuasan siswa MTs. Unggulan Mukhtar Syafaat Blokagung Tegalsari Banyuwangi Tahun Pembelajaran 2019/2020 tergolong cukup baik, karena hasil uji T hitung sebesar >1920 ta tabel, yang berarti Ha diterima; (3) adakah pengaruh layanan terhadap kepuasan siswa MTs. Unggulan Mukhtar Syafaat Blokagung Tegalsari Banyuwangi Tahun Pelajaran 2019/2020 sebesar 87,4\% sedangkan sisanya 12,6\% dipengaruhi oleh variabel lain yang tidak diteliti, yang berarti pengaruh layanan administrasi terhadap kepuasan siswa MTs. Unggulan Mukhtar Syafaat Blokagung Tegalsari Banyuwangi adalah sangat baik.
\end{abstract}

\section{Kata Kunci: Layanan Administrasi, Kepuasan Siswa}

Pengaruh Layanan Administrasi Terhadap Kepuasan Siswa MTs. Unggulan Mukhtar Syafaat Blokagung Tegalsari Banyuwangi Tahun Pembelajaran 2019/2020

Moh. Harun Al Rosid, Fila Nurul Arifin 


\begin{abstract}
The purpose of this study was to determine the quality of administrative services at MTs Unggulan Mukhtar Syafaat Benefits Blokagung Tegalsari Banyuwangi. Second, what is the level of satisfaction of the students at MTs Unggulan Mukhtar Syafaat Benefits Blokagung Tegalsari Banyuwangi. Third, is there an effect of service on the satisfaction of students at MTs Unggulan Mukhtar Syafaat Blokagung Tegalsari Banyuwangi. The method in this study uses quantitative data collection used in this study is a questionnaire, observation, and documentation. While the data validity test uses the Product moment formula, to find data reliability using the Cronbach Alpha formula. Then to test the hypothesis using the T-test and F test, while for the normality test using the Kolmogorov-Smirnov formula. In data analysis using Simple Linear Regression analysis. The results of this study indicate that: (1) the quality of administrative services at MTs Featured Mukhtar Syafaat Blokagung Tegalsari Banyuwangi for the 2019/2020 academic year is quite good, because the results of the T-test are 26.038> 1,290 t table., Which means that Ha is accepted; (2) the level of satisfaction MTs Featured students Mukhtar Syafaat Blokagung Tegalsari Banyuwangi Academic Year 2019/2020 is quite good, because the results of the $T$ count is > 1920 ta table, which means Ha is accepted; (3) is there an effect of service on the satisfaction of students of MTs Featured Mukhtar Syafaat Blokagung Tegalsari Banyuwangi Year The 2019/2020 lesson was $87.4 \%$ while the remaining $12.6 \%$ was influenced by other variables that were not studied, which means that the effect of administrative services on student satisfaction at MTs Unggulan Mukhtar Syafaat Blokagung Tegalsari Banyuwangi is very good.
\end{abstract}

Keywords: Effect of Administrative Services, Student Satisfaction

\title{
A. Pendahuluan
}

Sekolah merupakan instansi yang sangat penting didalam dunia ini, karena dengan adanya sekolah maka diharapkan kehidupan bangsa menjadi kuat. Menurut Undang-Undang SISDIKNAS No. 20 Tahun 2003 mengartikan pendidikan sebagai usaha sadar dan terencana untuk mewujudkan suasana belajar dan proses pembelajaran agar peserta didik secara aktif mengembangkan potensi dirinya untuk memiliki kekuatan spiritual keagamaan , pengendalian diri, kepribadian, kecerdasan, akhlaq mulia, serta keterampilan yang dapat membekali ketika terjun di masyarakat. Namun dalam hal ini pendidikan yang berkualitas mencakup mutu yang baik dari segi pembelajaran, lulusan, karakter, dan administrasi sekolah (dari segi kepegawaian,

Pengaruh Layanan Administrasi Terhadap Kepuasan Siswa MTs. Unggulan Mukhtar Syafaat Blokagung Tegalsari Banyuwangi Tahun Pembelajaran 2019/2020

Moh. Harun Al Rosid, Fila Nurul Arifin 
keuangan, sarana dan prasarana, hubungan sekolah dengan masyarakat, persuratan dan pengarsipan, kesiswaan, kurikulum, dan layanan khusus).

Administrasi sekolah sangatlah penting untuk proses terlaksananya kegiatan belajar mengajar yang relevan, efektif, efisien guna tercapainya tujuan pendidikan yang diharapkan. Adapun administrasi kesiswaan meliputi penerimaan siswa baru, pengelolaan dan penyuluhan, pengolahan kelas, pengolahan Organisasi Siswa Intra Sekolah (OSIS) dan pengolahan data tentang siswa dan sebagainya. Dalam pengelolaan administrasi kesiswaan yang baik dapat ditandai dengan tepat sasaran, cepat, tanggap, dan memuaskan bagi penerima jasa layanan misalnya peserta didik. Jadi untuk lembaga sekolah harus tetap mempertahankan pengelolaan administrasi yang baik, agar penerima jasa merasa puas dengan adanya layanan yang baik.

Selain itu, menurut Diana (2008: 187), setiap muslim juga diperintah untuk memberikan pelayanan yang ramah, sesuai hadist berikut:

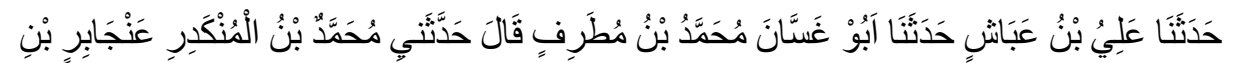

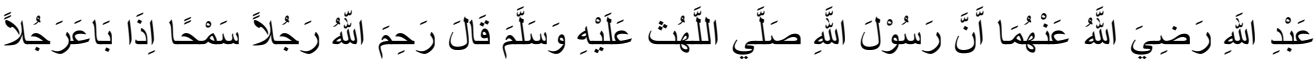

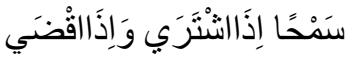

Artinya: "Telah menceritakan kepada kami Muhammad bin Sulaiman Al Mishshishi, telah menceritakan kepada kmai Muhammad bin Az Zibriqon, dari Abu Hayyan At Taimi, dari ayahnya dari Abu Hurairah dan ia merafa'kannya. Ia berkata; sesungguhnya Allah berfirman: 'Aku adalah pihak ketiga dari dua orang yang bersekutu, selam tidak ada salah seorang diantara mereka yang berkhianat kepada sahabatny. Apabila ia telah mengkhianatinya, maka aku keluar dari keduanya." (HR. Abu Daud No. 2936)

Pada hadist di atas sudah dijelaskan bahwasanya dalam melakukan layanan administrasi harus beramanat, tidak terkecuali dengan melakukan layanan yang sesuai harapan siswa. Selaras dengan hal tersebut, kepuasan dan ketidakpuasan merupakan dampak dari perbandingan antara harapan konsumen sebelum melakukan pembelian yang diperoleh dari produk/jasa. Kepuasan merupakan suatu perasaan senang atau kecewa seseorang yang muncul setelah membandingkan kinerja atau hasil produk yang diterima terhadap kinerja yang diharapkan. Jika suatu kinerja pelayanan berada dibawah harapan pelanggan, maka pelanggan tidak akan merasa 
puas danjika kinerja pelayanan memenuhi harapan pelanggan, maka pelanggan akanmerasakan kepuasan tersendiri. Sebaliknya jika kinerja melebihi harapan maka pelanggan akan teramat puas atau senang.

Dalam Al-Qur'an Allah berfirman dalam surat al-Hajj 22 hal 78:

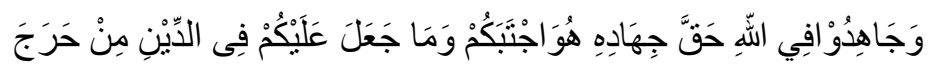

Artinya: "Dan berjihadlah kamu pada Allah dengan jihad yang sebenarbenarnya. Dia telah memilih kamu dan dia sekali-kali menjadikan untuk kamu dalam agama suatu kesempitan”. (QS. Al-Hajj: 78)

Pada ayat tersebut sudah dijelaskan diperlukan pengelolaan yang berani mengambil kebijakan atau memutuskan hal-hal yang berbeda dengan tuntutan atau petunjuk formal, oleh karena itu perlu menghidupkan kreativitas para pengelola lembaga predidikan maka perlu dikembangkan evaluasi yang berorientasi sesuai dengan hasil yang akan dicapai.

Berdasarkan profil yang didapat saat observasi, MTs Unggulan Mukhtar Syafaat adalah salah satu sekolah yang terletak di dusun Blokagung desa Karangdoro kecamatan Tegalsari kabupaten Banyuwangi profinsi Jawa Timur. Dan berada di naungan yayasan pondok pesantren Mukhtar Syafaat yang didirikan pada tahun 2014 M bertepatan pada tahun $1435 \mathrm{H}$. Berlokasi tepatnya, kurang lebih $45 \mathrm{~km}$ dari pusat kota Banyuwangi, $18 \mathrm{~km}$ dari arah kota genteng, $15 \mathrm{~km}$ dari arah kota jajag, dan 8 km dari arah kecamatan Tegalsari. Termasuk dalam layanan administrasi terhadap kepuasan siswa. MTs Unggulan Mukhtar Syafaat tidak adanya faktor penunjang ruang tunggu yang belum memenuhi kebutuhan siswa, sehingga siswa tersebut merasa kurang puas.

Berdasarkan hasil observasi awal dan survei pada tanggal 02 November 2019 dapat dijelaskan berbagai permasalahan tersebut adalah tidak adanya ruang tunggu dan fasilitas pendukung seperti koran dan sejenisnya, sehingga dapat membuat siswa jenuh dalam melakukan layanan administasi. Seperti yang dikemukakan oleh bapak Umar Hadi merupakan Kepala Tatausaha MTs Unggulan Mukhtar Syafaat:

Pengaruh Layanan Administrasi Terhadap Kepuasan Siswa MTs. Unggulan Mukhtar Syafaat Blokagung Tegalsari Banyuwangi Tahun Pembelajaran 2019/2020 
Bahwasanya layanan administrasi di MTs Unggulan Mukhtar Syafaat Blokagung Tegalsari Banyuwangi ini belum sepenuhnya memenuhi kepuasan yang diinginkan, karena kurangnya faktor ruang tunggu bagi siswa saat mengantri layanan administrasi, jadi untuk siswa biasanya hanya menunggu diluar dan merasa jenuh dalam melakukan layanan administrasi.

Tidak memanfaatkannya kotak saran untuk menjaring keluhan, sehingga dari pihak lembaga tidak mengetahui kekurangan dalam melakukan layanan administrasi. Adapun jika kontak saran tersebut bisa dimanfaatkan, maka lembaga tersebut akan bisa menindak lanjuti keluhan yang selama ini dirasakan oleh siswa. Sesuai dengan keterangan yang telah dipaparkan oleh bapak Umar Hadi bahwa:

Bahwasanya untuk layanan administrasi tentang memanfaatkan kotak saran masih belum diagendakan, mungkin untuk kedepanya akan dibuatkan kotak saran untuk siswa terkait dengan keluhan dalam layanan administrasi, agar dari tenaga tatausaha dapat memperbaiki layanan apabila pelayanan yang diberikan kurang memuaskan.

Tidak adanya jam layanan khusus untuk siswa yang akan melakukan pelayanan. Untuk layanan administrasi di MTs Unggulan Mukhtar Syafaat belum ada jam layanan tetap, oleh karena itu siswa dalam melakukan pembayaran kapanpun tanpa ada batas pada jam kegiatan, bahkan terkadang mengganggu jam pelajaran atau yang lainnya. Sesuai dengan pendapat yang dikemukakan oleh ibu noviani :

Terkait dengan layanan administrasi tentang tidak adanya jam layanan masih belum diterapkan di MTs Unggulan Mukhtar Syafaat, sehingga untuk siswa dalam melakukan pembayaran dilakukan kapan saja terkadang siswa juga menggangu jam istirahat. Adapun kedepanya akan di adakan jam layanan administrasi untuk siswa, agar siswa menjadi disiplin.

Berdasarkan hasil wawancara di atas sudah dijelaskan oleh informan Bapak Waka tatausaha bahwa layanan administrasi di MTs Unggulan Mukhtar Syafaat belum sesuai dengan harapan, oleh karena itu, perlu adanya evaluasi strategi dalam memberikan pelayanan yang baik. Salah satunya dengan cara bersikap sopan dan ramah dalam pelayanan, bersikap tanggap ketika ada siswa yang melakukan pelayanan. Adapun jika permasalahan diatas dibiarkan akan menimbulkan kerugian besar bagi sekolah, diantaranya dapat merusak nama baik sekolah tentang layanan 
yang kurang memenuhi kebutuhan masyarakat, sedang dalam lembaga sekolah harus menerapkan strategi pelayanan yang berkeadilan, efisien, response, akuntabel, dan partisipatif.

Pentingnya penelitian layanan administrasi yaitu untuk meningkatkan kualitas yang ada disekolah lebih baik, agar lembaga sekolah mampu bersaing diera globalisasi yang menuntut perkembangan ilmu pengetahuan dan teknologi yang semakin pesat, seperti banyaknya sekolah dan meningkatnya kebutuhan masyarakat sejalan dengan tantangan yang menyebabkan terjadi persaingan antar sekolah untuk memberikan layanan pendidikan yang lebih unggul. Cara untuk mempersiapkan diri dalam menghadapi globalisasi ini adalah dengan meningkatkan kesadaran dan memperluas wawasan tentang pengetahuan yang ada dilembaga sekolah. Salah satunya dengan meningkatkan kualitas pendidikan dengan memprioritaskan pengelolaan pendidikan.

Berdasarkan pemaparan di atas menjelasakan bahwa layanan administrasi terhadap kepuasan siswa merupakan pelayanan yang baik merupakan salah satu pilihan tepat dalam mengahadapi permasalah tersebut, karena layanan administrasi adalah suatu jasa yang tidak kasat mata dan tidak dapat diraba, tetapi jasa tersebut dapat dirasakan.yang ada di lembaga sekolah MTs Unggulan Mukhtar Syafaat Blokagung Tegalsari Banyuwangi penulis menemukan masalah-masalah dari hasil observasi awal di MTs Unggulan Mukhtar Syafaat Blokagung Tegalsari Banyuwangi sebagai berikut: Tidak adanya ruang tunggu dan fasilitas pendukung, tidak memanfaatkan kotak saran untuk menjaring keluhan, tidak adanya jam layanan khusus.

\section{B. Metode Penelitian}

Metode pada penelitian ini menggunakan kuntitatif dengan pengumpulan data yang digunakan dalam penelitian ini ialah angket, observasi, dan dokumentasi. Sedangkan uji validitas data menggunakan rumus Product moment, untuk mencari reliabilitas data menggunakan rumus Cornbach Alpha. Kemudian untuk uji hipotesis 
menggunakan uji $\mathrm{T}$ dan uji $\mathrm{F}$, sedangkan untuk uji normalitas menggunakan rumus Kolmogorov-Smirnov. Pada analisis data menggunakan analisis Regresi Linier Sederhana.

\section{Hasil dan Pembahasan}

Hasil penelian ini menunjukkan bahwa (1) kualitas layanan administrasi MTs Unggulan Mukhtar Syafaat Blokagung Tegalsari Banyuwangi Tahun Pembelajaran 2019/2020 tergolong cukup baik, karena hasil uji T hitung sebesar 26,038>1,290 t tabel., yang berarti Ha diterima;(2) tingkat kepuasan siswa MTs Unggulan Mukhtar Syafaat Blokagung Tegalsari Banyuwangi Tahun Pembelajaran 2019/2020 tergolong cukup baik, karena hasil uji T hitung sebesar >1920 ta tabel, yang berarti Ha diterima;(3) adakah pengaruh layanan terhadap kepuasan siswa MTs Unggulan Mukhtar Syafaat Blokagung Tegalsari Banyuwangi Tahun Pelajaran 2019/2020 sebesar $87,4 \%$ sedangkan sisanya $12,6 \%$ dipengaruhi oleh variabel lain yang tidak diteliti, yang berarti pengaruh layanan administrasi terhadap kepuasan siswa MTsUnggulan Mukhtar Syafaat Blokagung Tegalsari Banyuwangi adalah sangat baik.

Pembahasan pada penelitian ini yaitu:

1. Uji Validitas

Uji validitas merupakan cara untuk menguji apakah instrument yang digunakan dapat mengukur seharusnya diukur atau tidak. Dalam penelitian ini uji validitas dilakukan dengan membandingkan $r$ hitung dengan $r$ tabel.Apabila $r$ hitung lebih besar dari $\mathrm{r}$ tabel, maka perbedaan yang ada adalah signifikan, sehingga instrument bisa dinyatakan valid. Tingkat signifikan adalah 0,05 atau $5 \%$. Hasil uji validitas dengan menggunakan SPSS versi 22 pada tabel 1 berikut:

Pengaruh Layanan Administrasi Terhadap Kepuasan Siswa MTs. Unggulan Mukhtar Syafaat Blokagung Tegalsari Banyuwangi Tahun Pembelajaran 2019/2020 
Tabel 1. Hasil Uji Validitas Variabel (X) Layanan Administrasi

\begin{tabular}{|c|c|c|c|c|}
\hline No & Item Pertanyaan & $\begin{array}{c}\text { Corrected Item- } \\
\text { Total Correlation }\end{array}$ & r tabel 5\% & Kriteria \\
\hline 1. & X.1 & 0,456 & $>0,202$ & Valid \\
\hline 2. & X.2 & 0,403 & $>0,202$ & Valid \\
\hline 3. & X.3 & 0,324 & $>0,202$ & Valid \\
\hline 4. & X.4 & 0,531 & $>0,202$ & Valid \\
\hline 5. & X.5 & 0,402 & $>0,202$ & Valid \\
\hline 6. & X.6 & 0,485 & $>0,202$ & Valid \\
\hline 7. & X.7 & 0,467 & $>0,202$ & Valid \\
\hline 8. & X.8 & 0,469 & $>0,202$ & Valid \\
\hline 9. & X.9 & 0,377 & $>0,202$ & Valid \\
\hline 10. & X.10 & 0,447 & $>0,202$ & Valid \\
\hline 11. & X.11 & 0,394 & $>0,202$ & Valid \\
\hline 12. & X.12 & 0,448 & $>0,202$ & Valid \\
\hline 13. & X.13 & 0,537 & $>0,202$ & Valid \\
\hline 14. & X.14 & 0,388 & $>0,202$ & Valid \\
\hline 15. & X.15 & 0,342 & $>0,202$ & Valid \\
\hline 16. & X.16 & 0,368 & $>0,202$ & Valid \\
\hline 17. & X.17 & 0,526 & $>0,202$ & Valid \\
\hline 18. & X.18 & 0,370 & $>0,202$ & Valid \\
\hline 19. & X.19 & 0,451 & $>0,202$ & Valid \\
\hline 20. & X.20 & 0,411 & $>0,202$ & Valid \\
\hline
\end{tabular}

Sumber: Hasil Olah Data Penelitian, Juli 2020

Berdasarkan data pada tabel 4.4 di atas, dapat diketahui bahwa semua pengujian terhadap instrumen variabel $X$, nilai $r$ hitung lebih besar dari pada $r$ tabel, maka pertanyaan tersebut dikatakan valid. Diketahui bahwa $r$ tabel dari taraf signifikansi 0,05dengan dk 100-2 = 98 adalah 0,202. Dengan demikian semua pertanyaan dalam kuesioner dapat dinyatakan valid dengan cara mengumpulkan data yang diperlukan.

Tabel 2. Hasil Uji Validitas (Y) Kepuasan Siswa

\begin{tabular}{|c|c|c|c|c|}
\hline No & Item Pertanyaan & $\begin{array}{c}\text { Corrected Item- } \\
\text { Total Correlation }\end{array}$ & r tabel 5\% & Kriteria \\
\hline 1. & Y.1 & 0,331 & $>0,202$ & Valid \\
\hline 2. & Y.2 & 0,434 & $>0,202$ & Valid \\
\hline 3. & Y.3 & 0,286 & $>0,202$ & Valid \\
\hline 4. & Y.4 & 0,467 & $>0,202$ & Valid \\
\hline
\end{tabular}

Pengaruh Layanan Administrasi Terhadap Kepuasan Siswa MTs. Unggulan Mukhtar Syafaat Blokagung Tegalsari Banyuwangi Tahun Pembelajaran 2019/2020 


\begin{tabular}{|c|c|c|c|c|}
\hline 5. & Y.5 & 0,359 & $>0,202$ & Valid \\
\hline 6. & Y.6 & 0,290 & $>0,202$ & Valid \\
\hline 7. & Y.7 & 0,504 & $>0,202$ & Valid \\
\hline 8. & Y.8 & 0,386 & $>0,202$ & Valid \\
\hline 9. & Y.9 & 0,472 & $>0,202$ & Valid \\
\hline 10. & Y.10 & 0,467 & $>0,202$ & Valid \\
\hline 11. & Y.11 & 0,434 & $>0,202$ & Valid \\
\hline 12. & Y.12 & 0,467 & $>0,202$ & Valid \\
\hline 13. & Y.13 & 0,413 & $>0,202$ & Valid \\
\hline 14. & Y.14 & 0,504 & $>0,202$ & Valid \\
\hline 15. & Y.15 & 0,290 & $>0,202$ & Valid \\
\hline 16. & Y.16 & 0,472 & $>0,202$ & Valid \\
\hline 17. & Y.17 & 0,434 & $>0,202$ & Valid \\
\hline 18. & Y.18 & 0,286 & $>0,202$ & Valid \\
\hline 19. & Y.19 & 0,413 & $>0,202$ & Valid \\
\hline 20. & Y.20 & 0,434 & $>0,202$ & Valid \\
\hline
\end{tabular}

Sumber: Hasil Olah Data Penelitian, Juli 2020.

Berdasarkan data pada Tabel 2 diatas, diketahui bahwa nilai r tabel untuk dua sisi pada taraf kepercayaan $87,4 \%$ atau signifikansi $12,6 \%(\mathrm{p}=0,12)$ dapat dicari berdasarkan jumlah responden atau $\mathrm{N}$. Oleh karena $\mathrm{N}=100$, maka derajat bebasnya adalah $\mathrm{N}-2=20-2=18$. Pada buku-buku statistik, nilai $\mathrm{r}$ tabel atau sisi pada $\mathrm{df}=$ 18 dan $\mathrm{p}=0,12$ adalah 0,212. Pada bagian Corrected Item-Total Correlation, dapat dinyatakan valid.

Oleh karena itu, semua pengujian terhadap instrumen variabel $\mathrm{X}$, nilai $\mathrm{r}$ hitung lebih besar dari $r$ tabel. Dengan demikian, pertanyaan butir 1 sampai butir 20 dalam kuesioner tersebut dapat dinyatakan valid dan dapat digunakan untuk mengumpulkan data yang diperlukan.

\section{Uji Reliabilitas}

\section{a. Variabel $\mathbf{X}$}

Nilai Alpha Cronbach = 0,723 dengan jumlah pertanyaan 20 butir atau item. Nilai $r$ tabel untuk uji dua sisi pada taraf kepercayaan $95 \%$ atau signifikansi $5 \%$ $(\mathrm{p}=0,05)$ dapat dicari berdasarkan jumlah responden atau $\mathrm{N}$. Oleh karena $\mathrm{N}=$ 100, maka derajat bebasnya adalah $\mathrm{N}-2=100-2=.98$ Pada buku-buku statistik, nilai $r$ tabel satu sisi pada $\mathrm{df}=98$ dan $\mathrm{p}=0,05$ adalah 0,202 .

Pengaruh Layanan Administrasi Terhadap Kepuasan Siswa MTs. Unggulan Mukhtar Syafaat Blokagung Tegalsari Banyuwangi Tahun Pembelajaran 2019/2020 
Oleh karena nilai Alpha Cronbach $=0,723$ ternyata lebih besar dari $\mathrm{r}$ tabel $=$ 0,202; maka kuesuoner yang diuji coba terbukti reliabel. Nilai Alpha Cronbach $=0,723$ terletak diantara 0,600 hingga 0,800 sehingga tingkat reliabilitasnya adalah reliabel.

\section{b. Variabel Y}

Cronbach $=0,832$ dengan jumlah pertanyaan 20 butir atau item. Nilai $r$ tabel untuk uji dua sisi pada taraf kepercayaan 95\% atau signifikansi 5\% (p=0,05) dapat dicari berdasarkan jumlah responden atau $\mathrm{N}$. Oleh karena $\mathrm{N}=100$, maka derajat bebasnya adalah $\mathrm{N}-2=100-2=98$. Pada buku-buku statistik, nilai $\mathrm{r}$ tabel satu sisi pada $\mathrm{df}=98$ dan $\mathrm{p}=0,05$ adalah 0,202 .

Oleh karena nilai Alpha Cronbach $=0,832$ ternyata lebih besar dari $\mathrm{r}$ tabel $=$ 0,202; maka kuesuoner yang diuji coba terbukti reliabel. Nilai Alpha Cronbach $=0,832$ terletak diantara 0,800 hingga 0,100 sehingga tingkat reliabilitasnya adalah reliabel.

Berikut ini hasil uji reliabilitas variabel $\mathrm{X}$ dan variabel $\mathrm{Y}$ dengan menggunakan spss versi 22.

Tabel 3. Hasil Uji Reliabilitas Data

\begin{tabular}{|c|c|c|}
\hline Variabel & Cronbach's Alpha & Kriteria \\
\hline Layanan administrasi & 0,723 & Tinggi \\
\hline Kepuasan Siswa & 0,832 & Tinggi \\
\hline
\end{tabular}

Sumber: Olah Data Penelitian, Juli 2020.

Berdasarkan hasil analisis pada Tabel 3 menunjukkan bahwa nilai Cronbach's Alpha variabel X (Layanan Administrasi) dan variabel Y (Kepuasan Siswa) ada pada kriteria tinggi. Dengan hasil uji diatas dapat disimpulkan bahwa semua alat yang digunakan dalam penelitian ini adalah reliabel.

Pengaruh Layanan Administrasi Terhadap Kepuasan Siswa MTs. Unggulan Mukhtar Syafaat Blokagung Tegalsari Banyuwangi Tahun Pembelajaran 2019/2020 
Tabel 4. Hasil Uji Normalitas Data

\begin{tabular}{|cl|r|r|}
\hline & & LAYANAN & KEPUASAN \\
\hline $\mathrm{N}$ & Mean & 100 & 100 \\
Normal & Std. & 76.3100 & 76.7100 \\
Parameters & 7.94005 & 8.43549 \\
& Deviation & .056 & .080 \\
Most Extreme & Absolute & .056 & .080 \\
Differences & Positive & -.048 & -.062 \\
& Negative & .056 & .080 \\
Test Statistic & & $.200^{\mathrm{c}, \mathrm{d}}$ & $.116^{\mathrm{c}}$ \\
\multicolumn{2}{|c|}{ Asymp. Sig. (2-tailed) } & &
\end{tabular}

a. Test distribution is Normal.

b. Calculated from data.

c. Lilliefors Significance Correction.

d. This is a lower bound of the true significance.

Sumber: Output IBM SPSS V.22

Hasil uji normalitas menggunakan Kolomogorov-Smirnov pada Tabel 4 diatas dapat dilihat bahwa nilai taraf kesalahan 0,200 yang berarti lebih besar dari 0,05. Dari hasil tersebut jika diinterpretasikan dengan kriteria pengujian yaitu jika nilai signifikansi > 0,05, maka data berdistribusi normal. jadi dari hasil pengujian berarti bahwa nilai signifikansi 0,200 > 0,05 yang berarti data tersebut berdistribusi normal.

Tabel 5. Hasil Uji Linearitas

\begin{tabular}{|c|c|c|c|c|c|c|}
\hline & & $\begin{array}{r}\text { Sum } \\
\text { of Squares }\end{array}$ & $\mathrm{f}$ & $\begin{array}{l}\text { Mean } \\
\text { Square }\end{array}$ & $\mathrm{F}$ & Sig. \\
\hline \multirow{5}{*}{$\begin{array}{l}\text { KEPUASAN } \\
* \\
\text { LAYANAN }\end{array}$} & $\begin{array}{l}\text { Between (Combined) } \\
\text { Groups }\end{array}$ & 5629.523 & 1 & 181.598 & 20.182 & 0,000 \\
\hline & Linearity & 5453.132 & & 5453.132 & 606.036 & 0,000 \\
\hline & $\begin{array}{l}\text { Deviation } \\
\text { from } \\
\text { Linearity }\end{array}$ & 176.391 & 0 & 5.880 & 0.653 & 0,901 \\
\hline & Within Groups & 611.867 & 8 & 8.998 & & \\
\hline & Total & 6241.390 & 9 & & & \\
\hline
\end{tabular}

Sumber: Hasil Olah Data Penelitian, Juli 2020.

Pengaruh Layanan Administrasi Terhadap Kepuasan Siswa MTs. Unggulan Mukhtar Syafaat Blokagung Tegalsari Banyuwangi Tahun Pembelajaran 2019/2020 
Berdasarkan dari hasil uji linearitas pada Tabel 5 di atas, maka dasar pengambilan keputusannya berdasarkan nilai signifikansi. Diperoleh dari nilai signifikansi 0,901 yang artinya 0,901 > 0,05 maka dapat disimpulkan bahwa terdapat hubungan linear antara variabel X (layanan administrasi) dan variabel Y (kepuasan siswa).

Analisis data. Sebagaimana disampaikan pada bagian sebelumnya, bahwa penelitian ini menggunakan satu variabel bebas atau satu predicator. Oleh karena itu analisis data yang digunakan dalam penelitian ini adalah regresi linier sederhana. Kegunaan analisis regresi linier sederhana untuk mengukur besarnya pengaruh variabel bebas terhadap variabel terikat. Sebelum melakukan perhitungan pada rumus regresi linier sederhana, maka terlebih dahulu harus mengetahui jumlah skor $\mathrm{X}$ dan Y yang disajikan pada tabel berikut:

Tabel 6. Hasil Uji Regresi Linier Sederhana

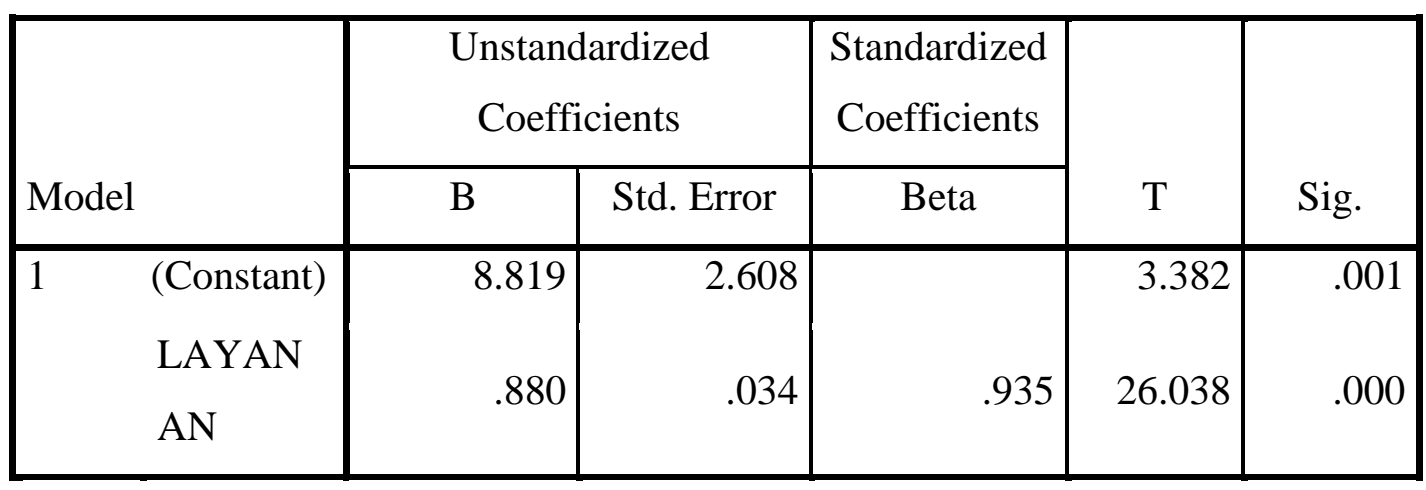

a. Dependent Variable: KEPUASAN

Sumber: Output IBM SPSS V.22

Berdasarkan Tabel 6 Konstanta $(\alpha)$ sebesar 69,372, menyatakan bahwa jika tidak ada layanan administrasi, maka kualitas pelayanan akademik adalah 0.880. Koefisien regresi (b) sebesar 0,880, menyatakan bahwa setiap penambahan (karena nilai koefisien regresi bernilai positif (+) satu skor layanan administrasi akan meningkatkan kepuasan siswa sebesar 0,880.

Pengaruh Layanan Administrasi Terhadap Kepuasan Siswa MTs. Unggulan Mukhtar Syafaat Blokagung Tegalsari Banyuwangi Tahun Pembelajaran 2019/2020 


\section{Tabel 7. Rata-rata Nilai Variabel X dan Y}

\begin{tabular}{|l|r|r|r|}
\hline & Mean & Std. Deviation & \multicolumn{1}{c|}{ N } \\
\hline KEPUASAN & 76.3100 & 7.94005 & 100 \\
LAYANAN & 76.7100 & 8.43549 & 100 \\
\hline
\end{tabular}

Sumber: Output IBM SPSS V. 22

Berdasarkan Tabel 7, diketahui bahwa nilai rata-rata (mean) layanan administrasi dengan jumlah data (N) 100 adalah 76.7100, dengan standar deviasi 8.43549. Ratarata (mean) kualitas kepuasan dengan jumlah (N) 10076.3100 adalah, dengan standar deviasi 7.94005

Tabel 8. Korelasi Nilai Layanan Administrasi dan Kepuasan Siswa

\begin{tabular}{|ll|r|r|}
\hline & & KEPUASAN & LAYANAN \\
\hline Pearson & KEPUASAN & 1.000 & 0.935 \\
Correlation & LAYANAN & 0.935 & 1.000 \\
\hline Sig. (1-tailed) & KEPUASAN & $\cdot$ & 0.000 \\
& LAYANAN & 0.000 &. \\
\hline $\mathrm{N}$ & KEPUASAN & 100 & 100 \\
& LAYANAN & 100 & 100 \\
\hline
\end{tabular}

Sumber: Output IBM SPSS V.22

Dari Tabel 8 dapat diperoleh dari besarnya korelasi 0,935, dengan signifikansi 0,000, karena signifikansi < 0,05 maka Ho ditolak dan Ha diterima. Artinya ada hubungan yang signifikan antara layanan administrasi terhadap kepuasan siswa.

Berdasarkan nilai koefisien korelasi yang positif 0,935, maka arah hubungannya adalah positif. Hal ini menunjukkan bahwa semakin baik kualitas layanan administrasi maka semakin baik pula kepuasan siswa dan begitu juga sebaliknya.

\section{Tabel 9. Variabel Masuk (Layanan Administrasi)}

Pengaruh Layanan Administrasi Terhadap Kepuasan Siswa MTs. Unggulan Mukhtar Syafaat Blokagung Tegalsari Banyuwangi Tahun Pembelajaran 2019/2020 


\begin{tabular}{|l|c|c|l|}
\hline Model & $\begin{array}{c}\text { Variables } \\
\text { Entered }\end{array}$ & $\begin{array}{c}\text { Variables } \\
\text { Removed }\end{array}$ & \multicolumn{1}{|c|}{ Method } \\
\hline 1 & LAYANAN $^{\mathrm{b}}$ & & Enter \\
\hline
\end{tabular}

a. Dependent Variable: KEPUASAN

b. All requested variables entered.

Sumber: Output IBM SPSS V.22

Pada Tabel 9. Variables Entered, menunjukkan bahwa variabel yang dimasukkan adalah variabel layanan administrasi dan tidak ada variabel yang dikeluarkan (removed), karena metode yang digunakan adalah metode enter.

Tabel 10. Hasil Uji Koefisien Determinasi $\left(\mathbf{R}^{2}\right)$

\begin{tabular}{|l|c|c|c|c|r|}
\hline Model & $\mathrm{R}$ & Square & $\begin{array}{c}\text { Adjusted R } \\
\text { Square }\end{array}$ & $\begin{array}{c}\text { Std. Error of the } \\
\text { Estimate }\end{array}$ & Durbin-Watson \\
\hline 1 & $0.935^{\mathrm{a}}$ & 0.874 & 0.872 & 2.83610 & 1.841 \\
\hline
\end{tabular}

a. Predictors: (Constant), LAYANAN

b. Dependent Variable: KEPUASAN

Sumber: Output IBM SPSS V.22

Pada Tabel 10, diperoleh dari hasil $R$ Square sebesar 0,874, angka ini adalah hasil pengkuadratan dari harga koefisien korelasi, atau $0,935 \times 0,935=0,874 . R$ Squaredisebut koefisien determinasi, yang berarti 87,4\% variabel kualitas pelayanan akademik dipengaruhi oleh variabel layanan administrasi, sisanya 12,6\% dipengaruhi oleh variabel lain yang tidak diteliti.

\section{Tabel 11. Hasil Uji Hipotesis F}

\begin{tabular}{|c|c|c|c|c|c|c|}
\hline & & $\begin{array}{l}\text { Sum of } \\
\text { Squares }\end{array}$ & Df & Mean Square & $\mathrm{F}$ & Sig. \\
\hline \multirow[t]{3}{*}{1} & Regression & 5453.132 & 1 & 5453.132 & 677.960 & $.000^{\mathrm{b}}$ \\
\hline & Residual & 788.258 & 98 & 8.043 & & \\
\hline & Total & 6241.390 & 99 & & & \\
\hline
\end{tabular}

a. Dependent Variable: KEPUASAN

b. Predictors: (Constant), LAYANAN

Sumber: Output IBM SPSS V.22

Pengaruh Layanan Administrasi Terhadap Kepuasan Siswa MTs. Unggulan Mukhtar Syafaat Blokagung Tegalsari Banyuwangi Tahun Pembelajaran 2019/2020 
Berdasarkan Tabel 11 ,diperoleh dari nilai F hitung sebesar 677,960, dengan tingkat signifikansi $0,000<0,05$, yang berarti model regresi yang diperoleh dapat digunakan untuk memprediksi kepuasan siswa.

Hasil analisis uji t dalam penelitian ini disajikan dalam tabel output SPSS sebagai berikut:

Tabel 12. Uji T hitung

\begin{tabular}{|c|c|c|c|c|c|c|}
\hline & \multirow[b]{2}{*}{ Model } & \multicolumn{2}{|c|}{$\begin{array}{l}\text { Unstandardized } \\
\text { Coefficients }\end{array}$} & \multirow{2}{*}{$\begin{array}{l}\text { Standardized } \\
\text { Coefficients } \\
\text { Beta }\end{array}$} & \multirow[b]{2}{*}{$\mathrm{T}$} & \multirow[b]{2}{*}{ Sig. } \\
\hline & & B & Std. Error & & & \\
\hline \multirow[t]{2}{*}{1} & (Constant) & 8.819 & 2.608 & & 3.382 & .001 \\
\hline & LAYANAN & .880 & .034 & .935 & 26.038 & .000 \\
\hline
\end{tabular}

a. Dependent Variable: KEPUASAN

Sumber: Output IBM SPSS V.22

Berdasarkan Tabel 12 dapat disimpulkan bahwa variabel manajemen layanan administrasi (X) t hitung sebesar 26,038 dibandingkan dengan t tabel dengan derjat kebebasan (dk) atau degree offreedom (df), $\mathrm{n}-2=100-2=98$ dengan menggunakan taraf signifikansi 5\% dan pengujiannya dengan menggunakan uji dua arah, maka $\mathrm{t}$ tabel diperoleh 1,290.

Dari hasil uji $\mathrm{t}$ di atas menghasilkan hasil uji $\mathrm{t}$ hitung $>\mathrm{t}$ tabel, yaitu 26,038>1,290, maka Ha diterima dan Ho ditolak. Hal tersebut dapat diartikan bahwa variabel layanan administrasi MTs Unggulan Mukhtar Syafaat Blokagung Tegalsari Banyuwangi tergolong cukup baik. Sedangkan pada hasil uji t diperoleh dari hasil hitung variabel kualitas pelayanan akademik sebesar 26,038 dibandingkan dengan t tabel pada derajat kebebasan (df) $100-2=98$, dan taraf signifikansi 5\% adalah 1,290. Hasil interpretasi dari t hitung > t tabel, maka Ha diterima. Jadi, hasil penelitian ini menunjukkan bahwa kepuasan siswa MTs Unggulan Mukhtar Syafaat Blokagung Tegalsari Banyuwangi tergolong cukup baik.

Pengaruh Layanan Administrasi Terhadap Kepuasan Siswa MTs. Unggulan Mukhtar Syafaat Blokagung Tegalsari Banyuwangi Tahun Pembelajaran 2019/2020 
Uji $\mathrm{F}$ atau uji koefisien regresi digunakan untuk mengetahui apakah variabel layanan administrasi (X) dan varibel kepuasan siswa (Y) secara signifikan atau tidak. Kesimpulan dari uji $\mathrm{F}$ ini dapat diperoleh dengan cara membandingkan $\mathrm{F}$ hitung dan $\mathrm{F}$ tabel dengan taraf signifikansi 0,05 atau 5\% . Kriteria pengambilan keputusannya adalah:

a) Apabila F hitung > F tabel, maka Ho ditolak dan Ha diterima, yang artinya variabel bebas secara simultan memiliki pengaruh yang signifikan terhadap variabel terikat

b) Apabila $\mathrm{F}$ hitung < F tabel, maka Ho diterima dan Ha ditolak, yang artinya variabel bebas tidak memiliki pengaruh yang signifikan terhadap variabel terikat.Hasil analisis uji $\mathrm{F}$ dalam penelitian ini disajikan dalam tabel berikut ini:

Tabel 13. Uji F hitung

\begin{tabular}{|rl|r|r|r|r|r|}
\hline \multicolumn{2}{|l|}{ Model } & \multicolumn{1}{|c|}{$\begin{array}{l}\text { Sum of } \\
\text { Squares }\end{array}$} & Df & Mean Square & F & Sig. \\
\hline 1 & Regression & 5453.132 & 1 & 5453.132 & 677.960 & $.000^{\mathrm{b}}$ \\
& Residual & 788.258 & 98 & 8.043 & & \\
& Total & 6241.390 & 99 & & & \\
\hline
\end{tabular}

\section{a. Dependent Variable: KEPUASAN \\ b. Predictors: (Constant), LAYANAN}

\section{Sumber: Output IBM SPSS V.22}

Berdasarkan hasil di atas pada Tabel 13, dapat diketahui bahwa F hitung sebesar 677,960 dibandingkan $\mathrm{F}$ tabel dengan (df) 100 - 2 = 98 dan taraf signifikansi 5\% yaitu 3,09 menghasilkan hasil uji $\mathrm{F}$ hitung > f tabel yaitu 677,960> 3,09, maka Ha diterima, yang berarti variabel bebas layanan administrasi (X) secara simultan memiliki pengaruh signifikan terhadap variabel terikat kepuasan siswa (Y).

Kualifikasi layanan administrasi. Pada bagian sebelumnya, telah dijelaskan permasalahan pertama pada penelitian ini yaitu bagaimana kualitas layanan administrasi terhadap kepuasan siswa MTs Unggulan Mukhtar Syafaat Blokagung 
Tegalsari Banyuwangi tahun pembelajaran 2019/2020. Setelah melakukan analisis data pengujian, berdasarkan dari uji t diperoleh dari hasil layanan administrasi (X) sebesar 26,038 dibandingkan t tabel dengan $\mathrm{n}=100-2$ dan taraf signifikansi $5 \%=$ dan pengujiannya menggunakan uji dua arah, maka t tabel diperoleh 1,290. Dari data tersebut, jika diinterprestasikan dengan kriteria pengujian adalah hasil uji thitung $>\mathrm{t}$ tabel, maka Ha diterima. Jadi hasil dari penelitian ini menunjukkan bahwa layanan administrasi MTs Unggulan Mukhtar Syafaat Blokagung Tegalsari Banyuwangi tahun pembelajaran 2019/2020 tergolong cukup baik.

Tingkat kepuasan siswa. Sesuai dengan hasil yang dijelaskan diatas permasalahan kedua dalam penelitian ini adalah bagaimana tingkat kepuasan siswa MTs Unggulan Mukhtar Syafaat Blokagung Tegalsari tahun pelajaran 2019/2020, sesuai dengan hasil yang dijelaskan diatas maka hasil penelitian ini menunjukkan bahwa uji t hitung diperoleh dari variabel tingkat kepuasan siswa (Y) 26,038 sebesar dibandingkan dengan t tabel yang mempunyai derajat kebebasan (dk) $100-2=98$ dan taraf signifikansinya 5\% sebesar 1,290. Hasilnya interpretasi t hitung $>\mathrm{t}$ tabel, maka Ha diterima. Jadi, hasil penelitian ini menunjukkan bahwa tingkat kepuasan siswa MTs Unggulan Mukhtar Syafaat Blokagung Tegalsari Banyuwangi tergolong cukup baik.

Pengaruh Antara Layanan dan Kepuasan Siswa MTs Unggulan Mukhtar Syafaat Blokagung Tegalsari Banyuwangi.Hasil dari pengujian regresi linier sederhana adalah untuk mengetahui seberapa besar pengaruh variabel bebas layanan administrasi (X) terhadap variabel terikat kualitas kepuasan siswa(Y). Dari hasil uji regresi linier sederhana, dapat disimpulkan bahwa pengaruh layanan administrasi sebesar $87,4 \%$ sisanya $12,6 \%$ dipengaruhi oleh variabel lain yang tidak diteliti. Secara konseptual pengaruh variabel layanan administrasi (X) terhadap variabel kepuasan siswa (Y) dapat digambarkan sebagai berikut:

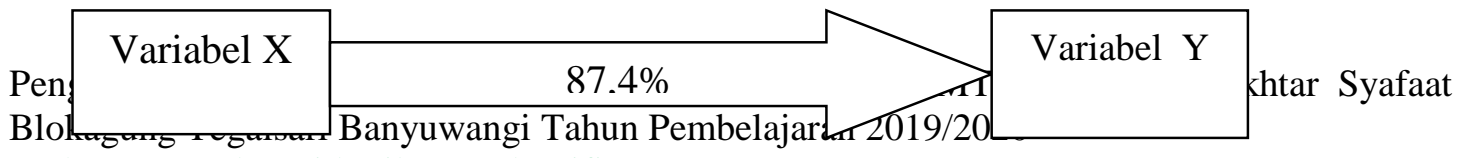




\section{Gambar 1. Model Persamaan Regresi}

\section{Kesimpulan}

Berdasarkan dari hasil pembahasan, analisis data, dan hasil penelitian, dan interpretasi, serta hasil data dilapangan, maka dapat diambil kesimpulan sebagai berikut: 1) Berdasarkan uji t hitung diperoleh dari variabel layanan administrasi (X) sebesar 26,038 dibandingkan dari t tabel dengan $\mathrm{n}=100-2=98$ dan taraf signifikansi $5 \%=1,290$. Dari data tersebut, jika diinterpretasikan dengan kriteria pengujian adalah hasil uji t hitung > t tabel, maka Ha diterima. Jadi hasil penelitian ini menunjukkan bahwa layanan administrasi MTs Unggulan Mukhtar Syafaat Blokagung Tegalsari Banyuwangi tahun pembelajaran 2019/2020 sangat baik. 2) Berdasarkan uji t hitung diperoleh dari variabel kepuasan siswa (Y) sebesar 26,038 dibandingkan dengan $\mathrm{t}$ tabel dengan derajat kebebasan (dk) $100-2=98$ dan taraf signifikansi 5\% sebesar 1,290. Hasilnya interpretasi t hitung > t tabel, maka Ha diterima. Jadi, dari hasil penelitian ini menunjukkan bahwa kepuasan siswa MTs Unggulan Mukhtar Syafaat Blokagung Tegalsari Banyuwangi sangat baik. 3) Berdasarkan perhitungan yang dilakukan dengan menggunakan rumus regresi sederhana dengan prosentase nilai RSquare sebesar $87,4 \%$ sisanya dipengaruhi oleh variabel lain yang tidak diteliti.

\section{E. Daftar Pustaka}

Al-Arif. 2010. Dasar-Dasar Pemasaran Bank Syariah. (Bandung: Alfabeta)

Arief. 2007. Pemasaran Jasa dan Kualitas Pelayanan. (Malang: Boyomedia Publishing)

Departemen Agama Republik Indonesia. 2002. Al-Qur'an dan Terjemahan. (Semarag: PT. Karya Toha Putra)

Diana. 2008. Hadis-Hadis Ekonomi. (Malang: UIN- Malang Press)

Hani, Handoko. 2009. Manajemen. (Yogyakarta: BPFE, Edisi Kedua)

Irfan, Fahmi. 2015. Manajemen Strategis Teori dan Aplikasi. (Bandung: Alfabeta)

Pengaruh Layanan Administrasi Terhadap Kepuasan Siswa MTs. Unggulan Mukhtar Syafaat Blokagung Tegalsari Banyuwangi Tahun Pembelajaran 2019/2020

Moh. Harun Al Rosid, Fila Nurul Arifin 
Kotler, Phiplip. 1999. Manajemen Pemasaran. (Jakarta: PT. Indeks, Edisi kedua belas)

Lupriyoadi, Rambut. 2008. Manajemen Pemasaran Jasa. (Jakarta: Salemba Empat, Edisi kedua)

Ratminto. 2012. Manajemen Pelayanan. (Yogyakarta: Pustaka Pelajar)

Siagian, P. Sondang. 2012. Manajemen Strategik. (Jakarta: Bumi Aksara)

Sinambela, Lijan Poltak. 2011. Reformasi Pelayanan Publik Teori Kebijakan dan Implementasi. (Jakarta: PT. Bumi Aksara)

Sugiono. 2016. Metode Penelitian Kuantitatif, Kualitatif dan R\&D. (Bandung: Alfabeta)

Sugiono. 2015. Metode Penelitian Pendidikan. (Bandung: Alfabeta)

Sugiyono. 2012. Metode Penelitian Administrasi dilengkapi dengan metode R\&D. (Bandung: Alfabeta)

Sunu, Pramudya. 1999. Peran SDM dalam Penerapan ISO 9000. (Jakarta: Gramedia Widiasarana Indonesia)

Suryani, 2011. Studi Komparatif Tingkat Kepuasan Siswa Terhadap Penyelenggaraan di Institut Pertanian Bogor, Skripsi. (Bogor: Fakultas Ekonomi dan Manajemen Institut Pertanian Bogor)

Susetyo, Budi. 2010. Statistik untuk Analisis Data Penelitian, (Bandung: Relika Aditama)

Syakuro, 2002. Pengaruh Peningkatan Pelayanan dengan Prinsip-Prinsip Syariah Terhadap Kepuasan Pelanggan. (Semarang: Ilmu Ekonomi Islam Fakultas Syariah Institut Agama Islam Negeri Walisongo)

Pengaruh Layanan Administrasi Terhadap Kepuasan Siswa MTs. Unggulan Mukhtar Syafaat Blokagung Tegalsari Banyuwangi Tahun Pembelajaran 2019/2020 